15. ГАПО. Ф. 2576. ОП. 1. Д. 30. Л. 10.

16. ГАПО. Ф. 2417. Оп. 1. Д. 221. Л. 11

17. Лет легендарных перекличка: Куйбышевский комсомол за 50 лет в цифрах, фактах, документах. Куйбышев: Кн. изд-во, 1968. 430 с.
18. Валеев А.М. Развитие физической культуры и спорта на Дальнем Востоке в 1945-1955 гг. // Теория и практика общественного развития. Исторические науки. 2014. № 4. С. 153-155.

19. ЦГАСО. Ф. 1230. Оп. 122. Д. 17. Л. 15

\title{
PHYSICAL CULTURE AND SPORT IN THE DAILY LIFE OF STUDENTS IN THE FIRST POST-WAR DECADE (ON THE MATERIALS OF KUYBYSHEV, PENZA, ULYANOVSK REGIONS)
}

(C) 2018

\author{
Kozlovskaya Galina Efimovna, doctor of historical sciences, professor, director \\ Samara branch of Moscow City Pedagogical University (Samara, Russian Federation) \\ Lubaeva Aleksandra Sergeevna, teacher of history \\ Gymnasia «Perspective» of Samara Urban Okrug (Samara, Russian Federation)
}

\begin{abstract}
The paper is devoted to one of the problems of the Soviet everyday life of young people - the process of physical culture and sports development among students of higher educational institutions in the postwar period (1945-1955). The author examines students' activity in sport sections, system of boys and girls health status control, analyzes the state of the material-technical base of universities to conduct classes in physical culture and sport in the first postwar decade. The author tries to reconstruct the joint activities of the leadership of higher education institutions and their students aimed at rebuilding the destroyed military infrastructure. The paper shows basic steps that could help to improve physical and sports work among students in accordance with the orders of the Soviet government in the difficult post-war period. The study introduced into scientific circulation documents of the State archive of the Penza Region. On the basis of archival materials the author provides information about the achievements and participation of Kuibyshev, Ulyanovsk and Penza students in sports competitions of various levels in both individual and team Championships. The paper contains a conclusion about sports clubs and sports organizations work aimed at promotion of physical culture and sports among students in the post-war everyday life.

Keywords: everyday life; students; sport; physical culture; university; students; physical development; GTO; postwar decade; material and technical base; Kuybyshev Region; Penza Region; Ulyanovsk Region.
\end{abstract}

УДК 314.4

Статья поступила в редакцию 21.03.2018

\section{ЭПИДЕМИЧЕСКИЙ ПЕРЕХОД У ГОРОДСКОГО НАСЕЛЕНИЯ СРЕДНЕГО ПОВОЛЖЬЯ} (C) 2018

\author{
Румянцева Мария Александровна, кандидат исторических наук, \\ доцент кафедры экономики и менеджмента \\ Филиал Самарского государственного технического университета в г. Новокуйбышевске \\ (2. Новокуйбышевск, Самарская область, Российская Федераџия)
}

Аннотаиия. Эпидемический переход является важнейшей частью перехода демографического, который, в свою очередь, определяет современные тенденции рождаемости и смертности в современной России. В статье сделана попытка на примере Среднего Поволжья проследить основные региональные особенности процесса. Используя данные статистики, отраженные в переписях, статистических сборниках, материалах центральных и местных архивов, автор прослеживает изменения в заболеваемости и смертности городского населения Среднего Поволжья, делая вывод, что эпидемический переход в регионе основном завершился в период хрущевской оттепели. Наблюдался также быстрый рост смертности от злокачественных новообразований и болезней системы кровообращения, что как раз и характерно для завершающей стадии эпидемического перехода. Выявленное автором статьи некоторое «отставание» региона по уровню экзогенной заболеваемости связано было с быстрым ростом промышленности в регионе и, как следствие, не всегда надлежащими условиями гигиены и быта городского населения. Однако тенденции смертности в Среднем Поволжье соответствовали таковым по РСФСР в целом, что было связано в первую очередь с достижениями медицины того времени: появлением антибиотиков, массовой вакцинацией населения, улучшением качества оказания медицинских услуг.

Ключевые слова: Среднее Поволжье; Куйбышевская область; Ульяновская область; Татарская АССР; городское население; средняя продолжительность жизни; заболеваемость; смертность; эпидемический переход; демографический переход; хрущевская оттепель; историческая демография; естественное движение населения; статистика; 1950-1960-е годы.

Динамика смертности населения является одним из важнейших процессов его демографического развития. Без уяснения тенденций данного процесса правильное понимание демографического развития населения невозможно [1].

Современные демографы для описания исторической эволюции демографических процессов исполь- зуют теорию демографического перехода [2-7]. Согласно данной теории, в демографической истории последовательно сменяются четыре типа воспроизводства населения, которые нередко называют также стадиями демографического перехода. Первый тип воспроизводства характеризуется высоким уровнем рождаемости и смертности, при этом естественный 
прирост либо отсутствует, либо очень низок, а в отдельные периоды может быть даже отрицательными. Подобный тип воспроизводства получил название экстенсивного. Второй тип связан с уменьшением смертности при сохраняющейся высокой рождаемости, что в ряде случаев привело к столь быстрому естественному приросту, что он получил в литературе наименование «демографического взрыва». Третий характеризуется сокращением естественного прироста из-за уменьшения рождаемости, тогда как снижение смертности замедляется по мере приближения к нулевой отметке. И последний тип связан со стабилизацией рождаемости и смертности на низком уровне, сближение которых ведет к сокращению роста населения, а нередко и к депопуляции.

Эпидемический переход является важной частью демографического перехода - основой для перераспределения смертности к старческим возрастам. Вызвано же снижение смертности изменениями в структуре факторов смерти. Экзогенные (голод, эпидемии, войны и т.п.) причины смерти уступают свое место эндогенным (онтобиологическим факторам развития и старения человеческого организма) и квазиэкзогенным (экологические и производственные факторы) причинам [8]. Происходит это вследствие того, что инфекционные и паразитарные заболевания все реже ведут к смерти, тогда как увеличивается смертность от болезней системы кровообращения, новообразований и т.п.

Одной из проблем при рассмотрении эпидемического перехода является выявление его региональных особенностей, чему мы и намереваемся посвятить данную статью. Особенностям эпидемического перехода в России посвящен ряд работ советских и современных историков и демографов (на наш взгляд, стоит обратить внимание на работы Е.М. Андреева, Л.Е. Дарского, Т.Л. Харьковой, В.Б. Жиромской, В.А. Исупова, В.Г. Семеновой и др.) [9-11]. Однако подобных работ по Среднему Поволжью нами выявлено не было.

В Среднем Поволжье, как и в стране в целом, эпидемический переход проходил в основном в 50 60-е годы XX века. В указанное десятилетие уровень смертности в регионе изменился незначительно. Однако динамика данного показателя существенно отличалась от ситуации в РСФСР. В 1956 году в Среднем Поволжье смертность почти повсеместно была выше, чем в целом по РСФСР, но к 1965 году смертность в регионе уже ниже, чем в РСФСР [12, с. 161-162].

Самой низкой смертность на 1000 населения была в промышленно развитых районах Среднего Поволжья - Куйбышевской области и Татарской АССР. Здесь была выше обеспеченность врачами на душу населения (4,3\%о в ТАССР против $3,1 \%$ в Ульяновской области). Именно поэтому выявленная заболеваемость в Куйбышевской области и Татарской АССР выше, а смертность ниже, чем в целом по региону $[1 ; 13$, л. $1,8,9,10 ; 14$, л. 4, 48, 64, 81, 96; 15; 16 , с. $220 ; 17$, с. $9-14 ; 18$, с. 489$]$. Неблагоприятная же экология промышленных центров еще не отразилась на росте смертности от эндогенных заболеваний (см. ниже) [1].

Как показали исследования советских демографов, увеличение показателя средней продолжитель- ности жизни в хрущевский период в стране связано в основном со снижением детской смертности. Как следствие, у мужчин показатель средней продолжительности увеличивается на $83 \%$ за счет снижения младенческой смертности и на $55 \%$ за счет снижения детской смертности. Тот же показатель для женщин увеличился на 76\% за счет снижения детской смертности и на $24 \%$ за счет уменьшения смертности при родах в фертильном возрасте [1; 19, л. 46, 118, 178; 20, л. 74, 74 об., 118, 118 об., 161, 161 об., 203, 203 об.; 21, л. 1-2 об., 72-73 об., 111-112 об., 151152 об., 181-182 об., 193, 193 об.; 22, л. 5, 11, 14, 16, 18 ; 23 , л. $77,124,159,204 ; 24$, л. $14 ; 25$, л. 80,124 , 169,$205 ; 26$, л. 6-7; 27, л. 1].

Показатели смертности в значительной мере зависят от социокультурных норм населения: соблюдения гигиенических норм, качества питания, доверия к медицинской помощи и своевременного обращения к ней и т.п. [1].

Несоблюдение гигиенических норм, низкое качество питания и медицинского обслуживания ведут к высокой смертности от экзогенных факторов смерти. В РСФСР в целом и в Поволжье в частности в конце 50-х - начале 60-х годов XX века были достигнуты значительные успехи в деле снижения инфекционной заболеваемости населения, особенно таких тяжелых заболеваний, как дифтерия, коклюш, тиф, малярия и др. [1].

Далее мы рассмотрим три группы инфекционных заболеваний: кишечные, детские и трансмиссионные инфекции.

В лечении детских инфекций в 60-е годы XX века были достигнуты большие успехи, особенно благодаря широкому внедрению вакцинопрофилактики. В середине 1950-х годов А. Сейбиным была разработана живая вакцина против полиомиелита, внедрение которой привело к снижению заболеваемости полиомиелитом в РСФСР в 50 раз, а в Среднем Поволжье в 43,3\% раза. Произошло снижение с сотен случаев в год до единичных [1; 28, с. 367].

Также в конце 1950-х годов была проведена широкая вакцинация детей вакциной АКДС: от дифтерии, коклюша и столбняка, что привело к снижению заболеваемости дифтерией по РСФСР в 36,7 раза и по Среднему Поволжью в 23,3 раза, а коклюшем по РСФСР в 4,2 раза, по региону в 2,5 раза. Однако не все еще детские инфекции были побеждены. Заболеваемость корью и скарлатиной была по-прежнему высокой, с характерным для таких заболеваний подъемом каждые 5-7 лет. К тому же росла и заболеваемость высококонтагиозными ветряной оспой и эпидемическим паротитом. Связано это было и с тем, что вакцин от данных болезней еще не было, и с ростом городского населения. Заболеваемость ветряной оспой возросла за указанный период по РСФСР в 1,6 раза (с 5,7 до 9,2\%о), по Среднему Поволжью в 1,5 раза (с 7,3 до 9,1\%), эпидемическим паротитом выросла в 3,1 раза (с 2,9 до 8,9\%о) по РСФСР и в 1,8 раза (с 4,9 до 8,9\%о) по Среднему Поволжью. Стоит, однако, признать, что из перечисленных детских болезней ветрянка и паротит всегда давали наименьшее количество смертельных исходов, так что рост заболеваемости ими не сказался на детской смертности [29, с. 67-71]. 
Одним из самых важных показателей эпидемического перехода является заболеваемость кишечными инфекциями, особенно тифами, паратифами, дизентерией, так как они являлись главными виновниками высокой смертности населения прошлых эпох. Заболеваемость этими инфекциями неуклонно снижалась, благодаря как широкому проведению противоэпидемических мероприятий, направленных на улучшение санитарно-гигиенического состояния коммунального хозяйства городов, так и тому, что в лучшую сторону изменилось благосостояние населения. В результате заболеваемость брюшным тифом, паратифами, энтеритами и гастроэнтеритами снизилась в 2-3 раза и в РСФСР, и в Среднем Поволжье. Заболеваемость же дизентерий в Поволжье уменьшилась значительно больше, чем в целом по РСФСР. Сравните, в РСФСР заболеваемость снизилась в 1,9 раза с 9,6\% до 5\%о, тогда как в Среднем Поволжье она снизилась в 3,1 раза с $11,9 \%$ до $3,9 \%$ и стала ниже, чем в РСФСР [29, с. 67-71].

Заболеваемость трансмиссионными инфекциями, такими как бруцеллез, сибирская язва, туляремия, малярия, снижается до единичных случаев. Связано это было с тем, что в 1954 году был получен новый препарат для лечения малярии - хлорохин. Кроме того, проводятся широкие мероприятия по ликвидации природных очагов распространения малярии обработка от комаров городов, парков и т.д. Поэтому малярия к 1960 г. была в СССР практически ликвидирована. Обработка от насекомых и грызунов территории городов и пригородов позволила справиться не только с малярией, но и с туляремией. Существенное уменьшение заболеваемости бруцеллезом и сибирской язвой связано было также с активными противоэпидемическими мероприятиями: наложением карантинов в очагах заболеваемости, лечением или уничтожением больных животных, обязательной термической обработкой продуктов животноводства в пищевой промышленности, санитарным контролем сырого мяса, вакцинацией людей, подвергающихся опасности заражения (с 1952 г. - прививка против бруцеллеза, с 40-х годов новая вакцина против сибирской язвы), и животных (с 1952 г. - массовая их вакцинация) [1; 28, с. 367].

Отдельно надо сказать о заболеваемости населения туберкулезом, снижение которой явилось одним из этапов общего снижения экзогенной заболеваемости населения [1]. Наиболее высокой была заболеваемость туберкулезом органов дыхания до $90 \%$ от всех выявленных больных [1], что не удивительно, так как именно эта форма туберкулеза является наиболее часто встречаемой. Основными способами передачи данного заболевания являются воздушнокапельный и контактно-бытовой. Это, несомненно, приводит к увеличению заболеваемости легочными формами туберкулеза на ранних стадиях урбанизации, что мы и наблюдаем в Среднем Поволжье в 1950-1960-х гг. Кроме того, и выявляемость в городах была выше [30, л. 51-53; 31, л. 54-56; 32, л. 135$136 ; 33$, л. 30-31; 34, л. 131-132; 35, л. 25; 36, л. 16 ; 37, л. 24, 24 об., 25, 25 об., 56, 56 об.].

Применение новых лекарственных препаратов, широкое распространение вакцинации населения, улучшение медицинского обслуживания явились главными причинами уменьшения смертности от экзогенных и квазиэкзогенных заболеваний. Этому также способствовало улучшение условий жизни населения и рост его гигиенической грамотности. Однако бурный рост промышленности в регионе приводил к ухудшению экологической и санитарноэпидемиологической обстановки, росту скученности населения, проблемам его быта, что не могло не привести к росту заболеваемости и смертности от рака, болезней сердца и нервной системы (в первую очередь от инфарктов и инсультов) [1].

Обращает на себя внимание рост смертности от злокачественных новообразований. К 1965 году уже каждый пятый умерший в городской местности Среднего Поволжья умирал от рака. Столь же высокой была и смертность от болезней сердца и органов кровообращения. Причем наблюдался быстрый рост смертности от данных причин. Особенно существенный у болезней сердца - в 2 раза за 10 лет. Болезни нервной системы, а также травмы и отравления тоже дают рост, правда не столь существенный, - около $10 \%$ на каждую из причин [38, с. 125; 39, л. 18 об., 56 об., 86 об.; 40, л. 72 об., 74 об., 76 об., 80 об.; 41, л. 50 об., 80 об., 110 об., 138 об.; 42, л. 41-50; 43, л. $38-41]$.

В то же время смертность от инфекционных заболеваний падает. Если в 1955 году смертность от дизентерии составляла 3,8\%, то в 1965 году смертности от этого заболевания уже не было [1]. Смертность от инфекционных заболеваний упала с 3,6\% до $2 \%$ за указанный период, от туберкулеза с $8 \%$ до $4,5 \%$, от болезней новорожденных с 4\% до $1,8 \%$, от болезней органов дыхания с 7,8\% до 4,4\% [1; 38, c. $125 ; 39$, л. 18 об., 56 об., 86 об.; 40, л. 72 об., 74 об., 76 об., 80 об.; 41, л. 50 об., 80 об., 110 об., 138 об.; 42, л. 41-50; 43, л. 38-41].

Таким образом, смертность от экзогенных заболеваний в регионе за период с 1955 по 1965 годы уменьшилась почти на 13\%, соответственно возросла смертность от эндогенных факторов.

При сравнении причин смертности в Среднем Поволжье и РСФСР следует обратить внимание на то, что смертность от экзогенных факторов в регионе была на 1,6\% выше, чем по РСФСР, за счет более высокой смертности от инфекционных заболеваний и туберкулеза, при этом смертность от болезней органов дыхания и особенно болезней новорожденных была в Среднем Поволжье ниже, чем по республике. В то же время смертность от травм и отравлений в регионе была на 3,5\% ниже, чем в РСФСР, а от болезней нервной системы на 7,3\% ниже [1]. Однако смертность от эндогенных факторов в Среднем Поволжье была на 5,2\% выше, чем в РСФСР. В основном потому, что было существенное расхождение в смертности от болезней системы органов кровообращения, которая в регионе превышала соответствующие показатели по республике на $13,5 \%$ [38, с. $125 ; 39$, л. 18 об., 56 об., 86 об.; 40, л. 72 об., 74 об., 76 об., 80 об.; 41, л. 50 об., 80 об., 110 об., 138 об.; 42, л. 41-50; 43, л. 38-41]. Это и являлось основными особенностями эпидемического перехода в Среднем Поволжье, связанными, несомненно, с активным промышленным строительством в регионе. 
Список литературы:

1. Румянцева М.А. Демографическая ситуация в городах Поволжья в 1955-1965 годах: дис. ... канд. ист. наук: 07.00.02. Самара, 2003. 208 с.

2. Кваша А.Я. Демографическая политика в СССР. М.: Финансы и статистика, 1981. 200 с.

3. Боярский А.Я. Население и методы его изучения. М.: Статистика, 1975, 264 с.

4. Вишневский А.Г. Воспроизводство населения и общество: история, взгляд в будущее. М.: Финансы и статистика, 1982. 287 с.

5. Вишневский А.Г. Демографическая революция. М.: Статистика, 1976. 240 с.

6. Брачность, рождаемость, смертность в России и в СССР: сб. статей / под ред. А.Г. Вишневского. М.: Статистика, 1977. 246 с.

7. Андреев В.М. Продолжительность жизни причины смерти в СССР // Демографические процессы в СССР. М., 1990. С. 90-92.

8. Андреев Е.М., Дарский Л.Е., Харькова Т.Л. Демографическая история России: 1927-1957. М.: Информатика, 1998. 197 с.

9. Жиромская В.Б. Основные тенденции демографического развития России в XX веке. М.: Кучково поле, 2012. $320 \mathrm{c}$.

10. Исупов В.А. Эпидемический переход в России: взгляд историка // Демографическое обозрение. 2016. T. 3, № 4. С. 82-92.

11. Семенова В.Г. Обратный эпидемиологический переход в России. М.: ЦСП, 2005. 235 с.

12. Репинецкий А.И., Румянцева М.А. Городское население Среднего Поволжья в послевоенное двадцатилетие. 1945-1965 гг.: очерки демографической истории. Самара: Изд-во «НТЦ», 2005. 262 с.

13. Российский государственный архив экономики (РГАЭ). Ф. 1562. Оп. 37. Д. 2615.

14. РГАЭ. Ф. 1562. Оп. 44. Д. 2601.

15. Текущий архив Самарского областного комитета государственной статистики (ТАСОКГС). Папка № 12. Л. 24-37.

\section{EPIDEMIOLOGICAL TRANSITION \\ OF THE URBAN MIDDLE VOLGA REGION POPULATION}

(C) 2018
16. Естественное и механическое движения населения РСФСР. М., 1960. 240 с.

17. Население Куйбышевской области от переписи 1959 г. до переписи 1979 г. Куйбышев: Статистика, 1980. С. 9-14.

18. Народное хозяйство РСФСР в 1958 г. М., 1959.508 c.

19. Государственный архив Российской Федерации (ГАРФ). Ф. А-374. Оп. 30. Д. 9629.

20. ГАРФ. Ф. А-374. Оп. 31. Д. 7841.

21. ГАРФ. Ф. А-374. Оп. 31. Д. 7850.

22. ГАРФ. Ф. А-374. Оп. 31. Д. 1845.

23. ГАРФ. Ф. А-374. Оп. 32а. Д. 7001.

24. ГАРФ. Ф. А-374. Оп. 35. Д. 3114.

25. ГАРФ. Ф. А-374. Оп. 35. д. 3115.

26. Центральный государственный архив Самарской области (ЦГАСО). Ф. Р-2521. Оп. 26. Д. 1037.

27. ЦГАСО. Ф. Р-2558. Оп. 10. Д. 1114.

28. Шувалова Е.П. Инфекционные болезни. 3-е изд., перераб. и доп. М.: Медицина, 1990. 558 с.

29. Румянцева М.А. Городское население Среднего Поволжья в 1956-1965 гг. Материалы к изучению демографической истории: сб. материалов и документов. Самара: СамГТУ, 2012. 176 с.

30. ГАРФ. Ф. А-374. Оп. 30 Д. 6883.

31. ГАРФ. Ф. А-374. Оп. 30 Д. 9666.

32. ГАРФ. Ф. А-374. Оп. 30 Д. 12026.

33. ГАРФ. Ф. А-374. Оп. 31 Д. 4957.

34. ГАРФ. Ф. А-374. Оп. 32 Д. 3105.

35. РГАЭ. Ф. 1562. ОП. 37 Д. 2711.

36. РГАЭ. Ф. 1562. ОП. 44 Д. 2774.

37. ЦГАСО. Ф. Р-2521. Оп. 25 Д. 905.

38. Репинецкий А.И. Демографический состав работников промышленности Поволжья (1945-1965).

Самара: СамГПУ, 1996, 132 с.

39. ГАРФ. Ф. А-374. Оп. 30. Д. 9643.

40. ГАРФ. Ф. А-374. Оп. 30. Д. 11996.

41. ГАРФ. Ф. А-374. Оп. 31. Д. 7853.

42. РГАЭ. Ф. 1565. Оп. 44. Д. 2625.

43. ЦГАСО. Ф. Р-4054. Оп. 4. Д. 735а.

\author{
Rumyantseva Maria Aleksandrovna, candidate of historical sciences, \\ associate professor of Economics and Management Department \\ Branch of Samara State Technical University in Novokuibyshevsk \\ (Novokuibyshevsk, Samara Region, Russian Federation)
}

\footnotetext{
Abstract. The epidemic transition is the most important part of the demographic transition, which in turn determines the current trends in fertility and mortality in modern Russia. The paper attempts to trace the main regional features of the process by the example of the Middle Volga Region. Using the statistics reported in the census, statistical handbooks, central and local archives, the author traces the changes in morbidity and mortality of the urban population of the Middle Volga Region, making the conclusion that the epidemiological transition in the region was essentially completed in the period of the Khrushchev thaw. There was also a rapid increase in mortality from malignant neoplasms and circulatory diseases, which is characteristic of the final stage of the epidemic transition. The author of the paper revealed some «lag» of the region in terms of exogenous morbidity. It was associated with the rapid growth of industry in the region, and as a consequence, not always appropriate conditions of hygiene and life of the urban population. However, mortality trends in the Middle Volga Region corresponded to those in the RSSR as a whole, which was primarily due to the achievements of medicine of the time: the emergence of antibiotics, mass vaccination of the population, improving the quality of medical services.

Keywords: Middle Volga Region; Kuibyshev Region; Ulyanovsk Region; Tatar ASSR; urban population; life expectancy morbidity; mortality; epidemic transition; demographic transition; Khrushchev thaw; historical demography; natural population movement; statistics; $1950-1960$.
} 